\title{
Carreira e Gestão de Pessoas nas Empresas "Big Four" a partir da Visão Auditores Externos
}

\author{
Career and People Management in the Big Four Companies from the External Auditors Vision
}

\author{
Carla dos Santos Feijó ${ }^{1}$ \\ Angela Beatriz Busato Scheffer ${ }^{2}$ \\ Jhony Pereira Moraes ${ }^{3}$ \\ Arthur Gehrke Martins Andrade ${ }^{4}$
}

\begin{abstract}
Resumo
Este estudo tem por objetivo entender como auditores externos de empresas Big Four percebem a sua carreira e qual a relação com a gestão de pessoas nessas organizações. Para isso, foi realizada uma pesquisa exploratória-descritiva, com abordagem qualitativa. Foram realizadas entrevistas semiestruturadas com 14 contadores, com experiência mínima de dois anos de trabalho em uma Big Four. Os resultados mostram que o trabalho em uma Big Four exige um conjunto de competências, principalmente técnicas e conceituais, mas também ligadas à atitude, não só para a formação da trajetória de carreira como também para a automanutenção do trabalhador nesse ambiente profissional. As políticas de treinamento e desenvolvimento se destacaram na opinião dos participantes, que se referem a elas como os principais atributos de atração, até mesmo sobrepondo-se à remuneração. A carreira numa Big Four é tipicamente organizacional (tradicional), entretanto, ela vem se modelando a partir das características das outras concepções de carreira: proteana, sem fronteiras, caleidoscópica e sustentável.
\end{abstract}

Palavras-chave: Carreira. Gestão de Pessoas. Big Four.

\begin{abstract}
This study aims to understand how external auditors from Big Four companies perceive their career and what is the relationship with people management in these organizations. For this, an exploratory-descriptive study with a qualitative approach was carried out. Semi-structured interviews were conducted with 14 accountants with at least two years of experience working in a Big Four. The results show that working in a Big Four requires a set of skills, mainly technical and conceptual, but also linked to attitude, not only for the formation of a career trajectory but also for the self-maintenance of the worker in this professional environment. The training and development policies stood out in the participants' opinion, who refer to them as the main attraction attributes, even overlapping the remuneration. A career in a Big Four is typically organizational (traditional); however, it has modeled itself on the characteristics of other career conceptions: protean, borderless, kaleidoscopic, and sustainable.
\end{abstract}

Keywords: Career, People management, Big Four.

Mestra em Gestão de Pessoas pela Escola de Administração da Universidade Federal do Rio Grande do Sul, especialista em Controladoria UFRGS.

Mestra e Doutora em Administração pela Universidade Federal do Rio Grande do Sul. Professora Associada na Escola de Administração da Universidade Federal do Rio Grande do Sul. Doutorando e Mestre em Administração pela UFRGS. Graduado em Administração pela UniRitter. É professor da Escola de Negócios da FADERGS Propaganda e Marketing (ESPM). Professor e Tutor na Faculdade FG. 


\section{INTRODUÇÃO}

A idealização de uma carreira próspera em auditoria ou consultoria, em uma das quatro maiores empresas mundiais especializadas nestes segmentos, conhecida como Big Four ${ }^{1}$ - Deloitte Touche Tohmatsu Auditores Independentes, Ernest \& Young Auditores Independentes, KPMG Auditores Independentes e PricewaterhouseCoopers Auditores Independentes - fascina muitos estudantes universitários e, principalmente, contadores.

É comum que estudantes universitários e, principalmente, alunos de cursos de Ciências Contábeis, queiram tornar-se trainees ${ }^{2}$ nessas empresas, visto que oferecem possibilidades de ascensão na carreira e status social no meio contábil. Iniciam como trainees e, com o tempo, usualmente são promovidos a auditores seniores, e posteriormente a gerentes e diretores, tendo futuramente a opção de se tornarem sócios dessas grandes empresas de auditoria e consultoria. Essas empresas, ao se apresentarem aos jovens estudantes, costumam valorizar as oportunidades e benefícios passíveis de serem adquiridos em termos de formação e trabalho, bem como oportunidades futuras. Desse modo, essas práticas e políticas de gestão de pessoas nessas empresas são destacadas como um diferencial na tentativa de atrair e reter os melhores profissionais.

Hall (1976) definiu carreira como uma sequência de atitudes e comportamentos associados com experiências de vida e atividades relacionadas ao trabalho, durante o período de vida de uma pessoa. Segundo este autor, a carreira no século XXI será predominantemente proteana, ou seja, dirigida pelas pessoas, não pelas organizações, e reinventada de tempos em tempos, diferente de uma época em que carreira estava associada à progressão linear e vertical, por uma maior estabilidade no emprego, e com a carreira estando voltada para a empresa. Enfoca-se, assim, que atualmente uma carreira autogerida é onde cada indivíduo deverá compor a sua carreira por meio da ampliação de suas competências e das experiências acumuladas ao longo de sua vida (HALL, 1976).

Ao se falar em trajetórias de carreira, se faz referência, então, à sequência de experiências de trabalho e de vida de uma pessoa ao longo do tempo. Mais ainda, entende-se aqui que com o passar dos tempos, o próprio conceito de carreira foi se ampliando, além do sentido meramente vinculado a uma ocupação, estando hoje relacionado a outras dimensões, como projeto de vida ou desenvolvimento pessoal (BENDASSOLLI, 2009a). Significa também que a carreira não é algo determinado, a priori, mas sim algo a ser construído, sugerindo um papel mais ativo do sujeito nesse processo. De acordo com Vieira et al. (2019), as carreiras (ou os entendimentos de carreira), mesmo que de origem anglo-americana, foram dispersando-se em diferentes realidades e regiões. Desse modo foram sendo desenvolvidos novos e múltiplos estudos que fossem capazes de refletir acerca das nuances que passaram a envolver as decisões de carreira, principalmente quanto aos relacionamentos entre empresas e indivíduos. Comércio global, tecnologias, diversidade da força profissional e transformações nas relações de trabalho, entre outros, fazem-se elementos centrais de análise. Sendo assim, é para a compreensão deste cenário de carreiras que vem se fortalecendo e determinando os rumos ocupacionais individuais e coletivos das últimas duas décadas. Junto a isso se percebe a constituição de laços de carreira com as e nas organizações cada vez menos tradicionais, estáveis, lineares e ascendentes (VIEIRA et al., 2019).

O início da carreira, ou o momento de inserção profissional das pessoas, costuma ser um período marcado por escolhas carregadas de expectativas, por vezes, bastante idealizadas. Considerando a importância do início das trajetórias de carreira em um contexto específico, o das grandes empresas de auditoria para o meio contábil, e as possíveis mudanças em torno da forma como se concebe carreira, tem-se como questão de pesquisa: de que maneira as práticas de gestão de pessoas exercem impacto na maneira como auditores externos das empresas Big Four percebem a própria carreira nessas organizações?

O estudo busca compreender as escolhas trilhadas por estes então jovens estudantes a partir da decisão por trabalhar em uma dessas grandes empresas de auditoria, em busca da realização profissional e pessoal, relacionando tais escolhas com as práticas de gestão de pessoas exercidas nestas organizações. Para tanto, foram entrevistados contadores hoje formados, com experiência profissional mínima de 10 anos, para que pudessem refletir sobre suas trajetórias ao longo dos tempos a partir da escolha por trabalhar em uma das Big Four.

Este artigo discute gestão de pessoas e carreira, segue com a apresentação da metodologia utilizada neste estudo e com os resultados da pesquisa, finalizando com considerações sobre o tema.

\section{FUNDAMENTAÇÃO TEÓRICA}

A fundamentação teórica a ser apresentada traz dois pontos de discussão: o primeiro faz referência à gestão de pessoas (GP), tratando a sua definição, o seu caráter estratégico nas organizações e também as políticas de GP utilizadas nesse contexto estratégico. O segundo ponto versa sobre a carreira, suscitando suas definições e as recentes concepções que emergem nesse campo.

1 É a nomenclatura comumente utilizada para representar as quatro maiores empresas de auditoria no mundo.

2 Trainee é o termo que representa os profissionais recém formados, ou em fase de encerramento de sua formação, contratados para um processo de treinamento em áreas específicas nas organizações. 


\subsection{Gestão de pessoas: definição e seu caráter estratégico}

A gestão de pessoas, enquanto área de conhecimento e setor nas organizações, envolve não somente o gerenciamento dos indivíduos, mas o trabalho que realizam e a cooperação entre aqueles para o alcance dos objetivos empresariais (PURCELL, 2003; GIL, 2009). Considerando-se a necessidade dos negócios, a gestão de pessoas assume cada vez mais um relevante papel de organizar os quadros profissionais, atraindo profissionais qualificados, ajudando-os no planejando de seus movimentos, em seu desenvolvimento, e favorecendo que se sintam valorizados de forma que possam melhor contribuir para o alcance dos resultados organizacionais.

Nesse sentido, são fundamentais políticas e práticas que estejam alinhadas à estratégia e aos desafios organizacionais, de modo a gerar competitividade organizacional (ULRICH, 1998; BOXALL; PURCELL, 2011; ASHTON; HAFFENDEN; LAMBERT, 2004; LENGNICK-HALL; ANDRADE; DRAKE, 2009). Alinhamento externo, numa ação mais contextual, e alinhamento interno, integrando a estratégia às políticas, práticas e aos processos como um todo. Ao fazer isso, a gestão de pessoas torna-se estratégica e pode promover um aspecto de diferenciação entre as organizações (BOXALL; PURCELL, 2011; ULRICH, 1998).

Em nosso país diversos teóricos se propuseram a analisar a atuação estratégica da gestão de pessoas nas organizações (ALMEIDA; TEIXEIRA; MARTINELLI, 1993; ALBUQUERQUE, 1999; FISCHER, 2002; LACOMBE; BENDASSOLI, 2004), como também enfatizaram as dificuldades, avanços, políticas e práticas empregadas pela área sob um cenário de transformações no mundo empresarial (CODA; CÉSAR; GARCIA, 2002; TANURE; EVANS; CANÇADO, 2010; CANÇADO et al., 2017).

Nesse sentido, Demo et al. (2011) reforçam a importância das políticas e práticas de GP em diferentes instâncias das organizações: para o comprometimento, desenvolvimento, valorização e retenção de talentos; como também para o alcance da produtividade, lucratividade e a qualidade das atividades, dos processos e do próprio trabalho dos funcionários. Em detalhe, os autores exploram as políticas de GP, resumindo-as em: a) recrutamento e seleção; b) envolvimento; c) treinamento, desenvolvimento e educação; d) condições de trabalho; e) avaliação de desempenho e competências; e f) recompensas. O Quadro 1 apresenta uma síntese dessas políticas.

$\mathrm{Na}$ elaboração das políticas e práticas de GP é fundamental considerar uma orientação para o estreitamento do perfil, dos valores e do potencial dos indivíduos à estratégia da empresa (PAROLIN, ALBUQUERQUE, 2011).

\section{Quadro 1 - Políticas de Gestão de Pessoas}

\begin{tabular}{|c|c|}
\hline $\begin{array}{l}\text { Política de gestão } \\
\text { de pessoas }\end{array}$ & Síntese das políticas de gestão de pessoas \\
\hline $\begin{array}{l}\text { Recrutamento e } \\
\text { seleção }\end{array}$ & $\begin{array}{l}\text { O Recrutamento envolve as atividades de identificação e atração de pessoas às oportunidades de trabalho. Essas } \\
\text { pessoas podem ser internas ou externas à empresa. Já a Seleção se refere à escolha por aquelas pessoas mais } \\
\text { qualificadas para os postos vagos dentre aquelas recrutadas. A política de recrutamento e seleção deve estar } \\
\text { alinhadas às demais políticas; os processos seletivos devem ser claros (informações completas aos candidatos, } \\
\text { critérios, resultados do processo seletivo), bem elaborados (atração de profissionais qualificados e competentes), } \\
\text { conduzidos por profissionais capacitados, imparciais e que estejam cientes das necessidades da organização (bem } \\
\text { como de suas características e seus processos). }\end{array}$ \\
\hline Envolvimento & $\begin{array}{l}\text { A política de envolvimento engloba ações que visam identificar competências e expectativas dos colaboradores. } \\
\text { Busca-se manter um ambiente de compreensão, cooperação, respeito, atenção e de bem-estar entre e com todos. } \\
\text { São realizados eventos para a integração dos funcionários. A importância das pessoas é elevada, sendo suas ideias, } \\
\text { sugestões e reclamações consideradas pelos gestores. Também são estimuladas a participar das tomadas de } \\
\text { decisão. }\end{array}$ \\
\hline $\begin{array}{c}\text { Treinamento, } \\
\text { desenvolvimento } \\
\text { e educação }\end{array}$ & $\begin{array}{l}\text { Essa política está voltada para a oferta de treinamentos on the job (internos), externos (eventos, seminários, } \\
\text { congressos) e combinados, bem como da educação a distância (cursos e palestras on-line), investimento em } \\
\text { universidades corporativas e financiamento parcial ou total em cursos de idiomas, de capacitação, graduação e/ } \\
\text { ou pós-graduação. Os treinamentos representam o esforço para facilitar a aprendizagem de comportamentos } \\
\text { necessários ao trabalho. O desenvolvimento objetiva capacitar o colaborador para atuação em diferentes postos de } \\
\text { trabalho. Por fim, a educação é orientada para o crescimento e amadurecimento do indivíduo. }\end{array}$ \\
\hline $\begin{array}{l}\text { Condições de } \\
\text { trabalho }\end{array}$ & $\begin{array}{l}\text { Refere-se aos benefícios oferecidos, o cuidado com o bem-estar e a saúde do trabalhador (qualidade de vida } \\
\text { no trabalho, programa de prevenção de doenças e estresse no trabalho, condições físicas apropriadas etc.), a } \\
\text { segurança (controle de acesso, manutenção das instalações e equipamentos, sistemas de segurança, contra } \\
\text { incêndio etc.); e a oferta de tecnologia adequada ao trabalho. Em resumo, as condições de trabalho se relacionam } \\
\text { ao cuidado da integridade do funcionário, proporcionando a ele um conjunto de benefícios, básicos e/ou } \\
\text { complementares. }\end{array}$ \\
\hline $\begin{array}{l}\text { Avaliação de } \\
\text { desempenho e } \\
\text { competências }\end{array}$ & $\begin{array}{l}\text { Essa política está relacionada às metas e aos resultados alcançados pelos funcionários, com o objetivo de } \\
\text { apontar as capacidades dos indivíduos para o alcance de resultados promissores. Além disso, busca colocar } \\
\text { os colaboradores na direção do desempenho desejado. As decisões são tomadas com base na avaliação dos } \\
\text { resultados apresentados. Para a avaliação de desempenho e competências são utilizadas escalas de avaliação } \\
\text { comportamental, por objetivos; avaliação } 360 \text { graus, entre outros. }\end{array}$ \\
\hline
\end{tabular}




\section{Quadro 1 - Políticas de Gestão de Pessoas (continuação)}

A política de recompensas tem por decisões como pagar e quanto pagar. Para tanto, busca-se alinhar as estratégias da área de gestão de pessoas com aquelas praticadas pelo mercado, sempre considerando os fatores contextuais. A remuneração deve ser compatível com a formação, com o que é oferecido pelo mercado; associada a um plano de carreira ou progresso funcional (quando houver); abranger as expectativas e sugestões dos colaboradores; ser customizada e condicionada aos resultados (quando possível e desejável). As remunerações podem ser compostas por bônus, prêmios, participação nos lucros e ações da empresa, e por funções comissionadas.

Fonte: elaborado pelos autores a partir de Demo et al. (2011).

\subsection{Carreira: conceitos e novos olhares}

É possível conceituar o termo carreira de diferentes formas. Sua conceituação varia de acordo com a literatura, sendo comum a utilização do termo carreira associada com a ideia de avanço; assim como de profissão; de sequência de trabalhos realizados ao longo da vida; e ou como uma sequência de experiências em funções relacionadas. Chanlat (1995) comenta que essa noção usual de carreira como uma profissão, numa sequência de etapas, é historicamente recente, aparecendo do decorrer do século XIX, assim como a ideia de que a empresa deve se preocupar com a gestão da carreira de seu pessoal é também recente, tendo aparecido nos anos 80. Hall (1996) e Chanlat (1995) apontam que esses modelos de carreira se caracterizavam por maior estabilidade no emprego e pela expectativa de progressão profissional (mais linear e vertical) ao longo de uma vida.

Entretanto, no final da década de 1990, novas abordagens surgiram, destacando mudanças nas concepções e nas relações de trabalho. Carreira passou a ser representada por modelos mais flexíveis (CHANLAT, 1995), estando associada a um processo de vida, permitindo que essa seja pensada independente de seu sentido unicamente ligada ao trabalho (HALL, 1976). Inkson (2004) fala em carreiras mais dinâmicas, em que os indivíduos se movimentam, seja no mesmo contexto profissional ou por entre contextos organizacionais e, até, entre áreas. Tais modelos apontam um papel mais ativo no sujeito na condução de suas carreiras: cabe a ele a condução de sua carreira, não mais a empresa.

Assim, diferentes abordagens hoje se apresentam para o estudo de carreiras, entre estas: carreira sem fronteiras (ARTHUR, 1994), carreira proteana (HALL, 1996), âncoras de carreira (SCHEIN, 1996; SCHEIN; VAN MAANEN, 2016), carreira caleidoscópica (SULLIVAN; MANIERO, 2008; O'NEILL; JEPSEN, 2019; MAINIERO; GIBSON, 2018) e carreira sustentável (DE VOS; HEIJEN, 2015, MÜLLER; SCHEFFER; CLOSS, 2020), que são sintetizadas no Quadro 2 abaixo.

Quadro 2 - Abordagens de Carreira

\begin{tabular}{|c|c|c|}
\hline Perspectiva & Ideia Central & Autor(es) \\
\hline $\begin{array}{l}\text { Carreira Sem } \\
\text { Fronteiras }\end{array}$ & $\begin{array}{l}\text { Carreira entendida como resultado de um repositório de conhecimento e uma fonte de } \\
\text { diferenciação para a empresa. A trajetória da carreira aparece menos como uma sequência } \\
\text { de posições e mais como um meio para acumular conhecimento explícito e tácito. Por } \\
\text { sua vez, carreiras sem fronteiras contribuem para a criação do conhecimento de maneiras } \\
\text { distintas, com consequências individuais, de grupo e organizacionais. Esse modelo é } \\
\text { caracterizado pela inexistência de limites à organização, ao emprego, à ocupação e à região } \\
\text { em que um indivíduo atua. }\end{array}$ & $\begin{array}{l}\text { Arthur (1994) } \\
\text { Grangeiro; Nadae; } \\
\text { Barreto (2020) }\end{array}$ \\
\hline $\begin{array}{l}\text { Carreira } \\
\text { Proteana }\end{array}$ & $\begin{array}{l}\text { Derivado do deus grego Proteus, que poderia mudar de forma de acordo com seu desejo, a } \\
\text { carreira proteana é dirigida pela pessoa e não pela organização e poderá ser reinventada de } \\
\text { tempos em tempos pelo indivíduo, conforme o ambiente e as pessoas forem passando por } \\
\text { modificações. }\end{array}$ & Hall (1994) \\
\hline $\begin{array}{c}\text { Carreira } \\
\text { Caleidoscópica }\end{array}$ & $\begin{array}{l}\text { Como um caleidoscópio que se modifica quando o tubo é rodado e suas lentes de vidro se } \\
\text { enquadram em novos arranjos, as mulheres (especialmente, mas a teoria também pode } \\
\text { referir-se aos homens) mudam o padrão de suas carreiras alterando diferentes aspectos de } \\
\text { suas vidas para organizar papéis e relacionamentos de novas maneiras. }\end{array}$ & $\begin{array}{l}\text { Sullivan; Mainiero } \\
\text { (2008) } \\
\text { Mainiero; Sullivan (2005) } \\
\text { O'neill; Jepsen (2019) } \\
\text { Maniero; Gibson (2018) }\end{array}$ \\
\hline $\begin{array}{l}\text { Carreira } \\
\text { Sustentável }\end{array}$ & $\begin{array}{l}\text { Sequência das diferentes experiências profissionais de um indivíduo, refletidas através de } \\
\text { uma variedade de padrões de continuidade ao longo do tempo, atravessando vários espaços } \\
\text { sociais e caracterizados pela agência individual, dando assim significado ao indivíduo. }\end{array}$ & $\begin{array}{l}\text { De Vos; Heijen (2015) } \\
\text { Müller; Scheffer; Closs } \\
(2020)\end{array}$ \\
\hline $\begin{array}{l}\text { Âncoras de } \\
\text { carreira }\end{array}$ & $\begin{array}{l}\text { Funciona como uma força estabilizadora, uma âncora e pode ser pensado como os valores } \\
\text { e motivos que a pessoa não renunciará caso precise fazer uma escolha. As âncoras de } \\
\text { carreira evoluem apenas quando se ganha experiência ocupacional e de vida. A maioria } \\
\text { de nós não está ciente de nossas âncoras de carreira até que sejamos forçados a fazer } \\
\text { escolhas relativas ao autodesenvolvimento, à família ou à carreira. }\end{array}$ & $\begin{array}{l}\text { Schein (1996) } \\
\text { Schein, Van Maanen } \\
(2016)\end{array}$ \\
\hline
\end{tabular}

Fonte: Elaborado pelos autores (2018) 
De modo geral, verifica-se, assim, um deslocamento da concepção de carreira voltada para a empresa como referência, para uma concepção mais individualizada (VIEIRA et al., 2019; FRAGA; ROCHA-DE-OLIVEIRA, 2020; GRANGEIRO; NADAE; BARRETO, 2020; MÜLLER; SCHEFFER; CLOSS, 2020). Segundo Fraga e Rocha-de-Oliveira (2020), as transformações socioeconômicas e organizacionais ao longo da última década incentivaram não apenas as empresas como os profissionais a repensarem as trajetórias de carreira, bem como produziram mudanças no mundo do trabalho, marcando a individualidade como algo central em um contexto de dinâmicas multifacetadas e inter-relacionadas (global, societal, cultural, de origem social e de trabalho - os dois últimos pontos também imbricados com a mobilidade profissional e internacional).

Nesse sentido, discutir carreira na contemporaneidade implica a problematização dos contextos nos quais os indivíduos exercitam a sua capacidade de agência (FRAGA; ROCHA-DE-OLIVEIRA, 2020). Portanto, quando se analisa carreira deve-se sempre considerar os múltiplos contextos (ou os microcontextos dos indivíduos) que estão sendo mobilizados em suas decisões de carreira, mesmo referindo-se a um perfil de carreira tradicional ou organizacional, uma vez que marcadores sociais de diferença (classe, raça, gênero, deficiência, nacionalidade, religião, sexualidade, entre outros) perpassam e definem as diferentes realidades de vida das pessoas (FRAGA; ROCHA-DE-OLIVEIRA, 2020).

A partir disso, observa-se que o conceito de carreira tradicional é insuficiente para explicar o desenvolvimento ou os cursos das carreiras nas organizações (GRANGEIRO; NADAE; BARRETO, 2020), mesmo que elas configurem o foco de análise e/ou refiram-se às organizações tradicionais, tal como são as Big Four. Por essa razão nota-se um esforço teórico em refletir as carreiras e seus percursos, de modo a fazer emergir novas classificações, características e compreensões, sempre retomando nesse processo o olhar sobre os contextos.

Entretanto, nesse contexto, em que vão se esgotando as promessas da carreira tradicional, ainda podemos encontrar empresas que centram suas ofertas de trabalho atrativo em possibilidades de "fazer carreira", como são as grandes empresas de auditoria. Meneses (2008) traz a questão do status de quem trabalha em uma multinacional como uma das Big Four, onde a perspectiva de crescimento e o peso no currículo, exaustiva e estrategicamente propagados pela mídia especializada, pesam nas escolhas de profissionais da área.

De acordo com Thiry-Cherques (2006), os dois modelos não são incompatíveis, pois a carreira, como sequência de posições sistematicamente ordenadas, não é incompatível com desejos de progressão e o desenvolvimento dos trabalhadores. Como salientam Delhvi e Süß (2016) e Baruch e Reis (2016), os movimentos percebidos desde os anos 1990 apontam para a individualização da construção de carreiras (não)organizacionais, isto é, dependentes ou não das organizações, no sentido de que os vínculos com as organizações afrouxam-se à medida que ao indivíduo é incubida a responsabilidade de decidir a sua trajetória e as suas estratégias de garantia da empregabilidade em um contexto de competitividade profissional cada vez mais acirrado e em um cenário de globalização das carreiras (BARUCH; REIS, 2016; MÜLLER; SCHEFFER; CLOSS, 2020).Veloso e Dutra (2010) consideram, inclusive, que as empresas de vanguarda estabelecem processos de gestão compartilhada de carreira, onde os indivíduos são responsáveis pelo planejamento de suas carreiras e a empresa pelo gerenciamento de oportunidades. Caberia às organizações prover tarefas desafiadoras, desenvolvimento de relações e recursos para o desenvolvimento dos trabalhadores.

É nesse contexto que se insere o presente estudo, examinar como auditores externos de Big Four percebem a sua carreira e a relação com as práticas e políticas de gestão de pessoas nessas organizações.

\section{METODOLOGIA}

Este estudo é de caráter exploratório-descritivo, com abordagem qualitativa em que o pesquisador vai a campo buscando "captar" o fenômeno em estudo a partir da perspectiva das pessoas nele envolvidas (GODOY, 1995).

Para a coleta de dados desta pesquisa foram realizadas entrevistas semiestruturadas com 14 contadores, que tiveram experiência mínima de dois anos, em pelo menos uma das quatro maiores empresas mundiais de auditoria (Big Four). Para a localização dos entrevistados foi utilizada a técnica de bola de neve, na qual o pesquisador solicitava aos respondentes se tinham indicações de pessoas com enquadramento no perfil estipulado para a pesquisa nas quais poderiam ser entrevistadas. As entrevistas, que duravam em média 12 horas, foram agendadas previamente e feitas em locais escolhidos pelos participantes, além de gravadas mediante consentimento para posterior transcrição. .

Para a análise das entrevistas foi utilizada a análise de conteúdo que, de acordo com Bardin (1991), é um método misto quantitativo/qualitativo, compreensivo e interpretativo, que se destina a descrever sistemática, objetiva e quantitativamente o conteúdo pesquisado.

Após a apresentação da metodologia da pesquisa passa-se a explorar os seus resultados.

\section{APRESENTAÇÃO E DISCUSSÃO DE RESULTADOS}

Antes de serem apresentados os principais resultados, cabe uma breve apresentação dos entrevistados: 
Quadro 3 - Perfil dos entrevistados

\begin{tabular}{|c|c|c|c|c|c|c|c|c|}
\hline 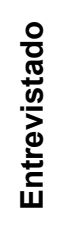 & 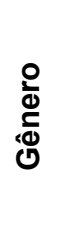 & 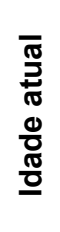 & 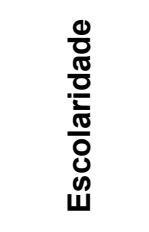 & 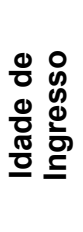 & 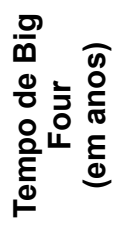 & 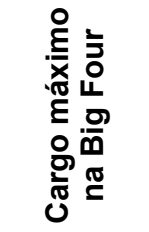 & 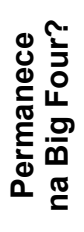 & $\begin{array}{l}\frac{0}{0} \\
\frac{\pi}{0} \\
\frac{0}{\pi} \\
\frac{\mathbb{J}}{2} \\
0\end{array}$ \\
\hline E1 & $\mathrm{F}$ & 36 & $C+D+E+M$ & 30 & 2 & Gerente & Não & Porto Alegre RS \\
\hline E2 & M & 34 & C & 21 & 12 & Gerente & Sim & São Paulo SP \\
\hline E3 & $\mathrm{F}$ & 33 & $\mathrm{C}+\mathrm{E}$ & 23 & 12 & Gerente & Não & Florianópolis SC \\
\hline E4 & $\mathrm{F}$ & 32 & $\mathrm{C}+\mathrm{M}$ & 22 & 2 & Sênior & Não & Porto Alegre RS \\
\hline E5 & $\mathrm{F}$ & 31 & $A+C+E$ & 24 & 6 & Top Sênior & Não & Porto Alegre RS \\
\hline E6 & $\mathrm{F}$ & 33 & $C+E$ & 23 & 3 & Sênior & Não & Indaiatuba SP \\
\hline E7 & M & 35 & $C+E$ & 27 & 3 & Sênior & Não & Porto Alegre RS \\
\hline E8 & M & 34 & C & 21 & 2 & Assistente & Não & Porto Alegre RS \\
\hline E9 & M & 32 & C & 21 & 11 & Diretor & Sim & São Paulo SP \\
\hline E10 & M & 35 & C & 23 & 11 & Gerente & Sim & Porto Alegre RS \\
\hline E11 & M & 33 & $C+E$ & 21 & 11 & Gerente & Não & Porto Alegre RS \\
\hline E12 & $\mathrm{F}$ & 31 & $C+E$ & 22 & 9 & Gerente & Sim & Porto Alegre RS \\
\hline E13 & M & 41 & C & 22 & 19 & Sócio & Sim & Porto Alegre RS \\
\hline E14 & M & 54 & $C+D+E$ & 26 & 26 & Sócio & Não & Porto Alegre RS \\
\hline
\end{tabular}

Fonte: Elaborado pelos autores (2018)

Legenda: As letras utilizadas na coluna Escolaridade referem-se a: C (graduação em Ciências Contábeis), D (graduação em Direito), A (graduação em Administração), E (Especialização), M (Mestrado).

Quanto aos 14 entrevistados, 12 deles possuem idade até 36 anos, sendo 6 mulheres e 8 homens. Seus tempos de trabalho nas Big Four variaram de quase 2 a 26 anos, sendo os cargos máximos atingidos por eles nessas empresas foram de assistente a sócio. Em relação à localização geográfica atual deles, dez residem em Porto Alegre/RS, dois em São Paulo, na capital e um no interior, e um em Florianópolis/SC. Dos cinco que permanecem trabalhando em alguma das Big Four, dois estão trabalhando em São Paulo e três em Porto Alegre. Assim, foram entrevistadas pelo menos duas pessoas de cada Big Four e uma pessoa da extinta Big Five.

Todos possuem graduação de nível superior em Ciências Contábeis e alguns têm segunda graduação (Direito ou Administração). Oito cursaram pós-graduação em nível de especialização e dois cursaram mestrado em Ciências Contábeis. Em relação às idades de ingresso na Big Four, a maioria dos entrevistados entrou até os 23 anos. Exceções a essa constatação foi o ingresso da entrevistada 1, sendo admitida aos 30 anos como gerente, e do entrevistado 14, que aos 38 anos ingressou como semissócio em uma Big devido sua experiência prévia na Big Five desde 1988.

Para fins de análise dos resultados desta pesquisa será trazida, agora, a percepção sobre as políticas e práticas de gestão de pessoas nas empresas de auditoria, discutindo-se sua relação com a trajetória de carreira. Para tanto, considerou-se as seguintes categorias: treinamento e desenvolvimento das pessoas, remuneração, ascensão de carreira e trajetórias de carreira.

\subsection{Treinamento e desenvolvimento}

Destaca-se nas entrevistas que as políticas de treinamento e desenvolvimento são valorizadas por agregar competências profissionais que se refletem na trajetória pessoal dos colaboradores, tal como é afirmado pelo entrevistado E5:

Eles investem em ti, em estudo, em desenvolvimento profissional, em faculdade, pós, estuda inglês, tudo o mais. Eu via que lá dentro eu conseguia ter esse benefício, foi um grande diferencial pra mim. Eu não me importava tanto com a questão do salário, mas sim o que eu ia me desenvolver 
lá dentro, porque eu não tinha condições financeiras de pagar uma faculdade, pagar uma pós, de pagar tudo o mais e precisava ter uma empresa que investisse em mim nisso (E5).

A partir desse relato cabe salientar que apesar dessas organizações oferecerem uma trajetória de carreira tradicional ou organizacional (HALL, 1976, 1996; CHANLAT, 1995) -com estágios de crescimento bem definidos -, as políticas de treinamento e desenvolvimento propostas contribuem para uma perspectiva subjetiva de carreira autogerida, ou proteana (HALL, 1994), uma vez que o conjunto de benefícios (como idioma e cursos de pós-graduação) se constitui como fator que reforça o "pensar em si", subsidiando um projeto de desenvolvimento pessoal desprendido de uma estrutura organizacional e de longo prazo. Assim, compreende-se que o indivíduo não se limita à estrutura da organização na qual está de passagem, pois busca fortalecer o propósito de vida que carrega consigo (GRANGEIRO; NADAE; BARRETO, 2020). Como diz E5: "Eu não me importava tanto com a questão do salário, mas sim o que eu ia me desenvolver lá dentro [...]".

A qualidade dos treinamentos das Big Four foi destacada por todos os entrevistados. Alguns mencionaram que eram excessivos, representando uma "avalanche de conhecimento", apesar de ser esperado por uma empresa desse porte (E8). Assim, o maior diferencial apontado de se trabalhar em uma Big Four foi o conhecimento adquirido através dos treinamentos e, também, pelo trabalho de campo nas empresas.

O entrevistado 2 (E2) contou sua visão do processo de treinamento neste tipo de empresa: "A gente não exige experiência na contratação de trainees porque a gente aposta na capacidade que a gente tem de treinar, e os treinamentos são internamente, são os mais experientes que treinam os menos experientes". Como se pode notar, os treinamentos técnicos foram muito mencionados, mas alguns, porém, evidenciaram os treinamentos comportamentais, que são importantes nessa profissão e tipo de empresa:

Como a gente cresce na carreira muito rápido, com 2, 3 anos tu já é líder de campo, já tem outras pessoas trabalhando pra ti. Então essa questão de como supervisionar, como ser um bom líder, dar $\mathrm{Coach}^{3}$, ter pessoas trabalhando pra ti, como cobrar, como lidar com as pessoas, também tem uma série de treinamentos bastante focados, bem importante (E3).

Já o entrevistado 9 (E9), que tem por escolha permanecer na Big, relatou que mesmo trabalhando por 11 anos nessa empresa, há sempre possibilidade de crescimento. Trouxe também sua experiência, proporcionada pela Big, de trabalhar no exterior por 2 anos, demonstrando um desenvolvimento não somente profissional mas, sobretudo, um desenvolvimento pessoal por ter a oportunidade de conviver com diferentes culturas, conforme relato a seguir:

É interessante tu trabalhar fora do país e ver, de certa forma, o que a empresa sendo tão grande consegue, de certa forma, uma cultura consistente, né. A cultura é muito similar. Por exemplo, onde eu estava lá, em Londres, era um departamento internacional, tinha gente do mundo inteiro, profissionais do mundo inteiro. Então tinham pessoas do Japão, Índia, Canadá, Estados Unidos, Alemanha, França, e embora tu não consiga entender características culturais diferentes, a cultura da empresa tu conseguia ver refletido nesses profissionais que se formaram em outros países (E9).

Dos 14 entrevistados, 6 tiveram vivências fora das fronteiras brasileiras e um tem ainda a expectativa de ter essa experiência: E2 pretende, em breve, fazer um intercâmbio proporcionado pela Big na qual trabalha; E3 trabalhou na Big nos Estados Unidos; E5 fez intercâmbio antes de ingressar na Big Four e lá teve 2 empregos; E9 relatou sua experiência em Londres proporcionada pela Big; E10 estudou, durante seu período na Big, mas não proporcionado por ela, no Reino Unido e no Canadá; E12 esteve um período afastada da Big para estudar no Canadá retornando à empresa após esta etapa fora; E14 trabalhou em outra Big, também em Londres. Chama a atenção que os países nos quais os entrevistados tiveram vivência são todos de língua inglesa, reforçando a importância do seu domínio neste tipo de organização.

De acordo com Gallon e Scheffer (2014) a opção de realizar experiências internacionais, que podem representar oportunidades de crescimento na carreira e também maior desenvolvimento para a sua empregabilidade futura no mercado de trabalho, é uma das possibilidades que o profissional encontra para se desenvolver e se destacar, no meio empresarial vigente.

Trilhar uma carreira organizacional ainda é uma realidade a ser alcançada por muitas pessoas, principalmente em ambientes empresariais bem estruturados, em empresas com status no mercado e que por isso geram maior peso no currículo, nos quais as políticas de treinamento e desenvolvimento se mostram atraentes e valorosas. Como nos relatos acima mostrados, essas políticas das Big Four sobressaem-se ao salário, pois tendem a ampliar constantemente o escopo de competências profissionais, também em contextos sócioculturais diferenciados, como

3 Palavra inglesa com a tradução de treinar. Usa-se esse termo também referente à evolução de cargos e carreiras nas grandes empresas. (ADICIONEI ESSA NOTA. CONFERIR SE O AUTOR CONCORDA). 
é o caso das experiências de trabalho no exterior. Frente aos demais conceitos de carreira (ARTHUR, 1994; HALL, 1994; MANIERO; SULLIVAN, 2005; SULLIVAN; MANIERO, 2008; DE VOS; HEIJEN, 2015; SCHEIN; VAN MAANEN, 2016; GRANGEIRO; NADAE; O'NEILL; JEPSEN, 2019; BARRETO, 2020; MÜLLER; SCHEFFER; CLOSS, 2020), a carreira organizacional se configura, a partir das percepções dos entrevistados no âmbito das políticas de GP aqui mencionadas, como estratégia objetiva ou subjetiva de aprimoramento e desenvolvimento pessoal. Constitui-se, assim, em uma via de acesso à maior qualificação e preparo para novas trajetórias de carreira em outras realidades empresariais, ou até mesmo como artefato de desenvolvimento pessoal quando associado às concepções de carreira proteana (HALL, 1994) e sem fronteiras (ARTHUR, 1994).

\subsection{Remuneração}

A maioria dos entrevistados relatou que a remuneração nessas empresas não é boa, quando comparada com o mercado de trabalho. Apesar disso, E2 traz sua visão a esse respeito: "Todo mundo reclama, mas eu acho que é problema de comparação, da forma como as pessoas comparam as coisas". Nesse sentido, E6 refere: "há uma rotatividade, tu deve ter percebido nas tuas entrevistas, muito grande nessa área, não é todo mundo que vê a carreira de auditoria como uma oportunidade de aprendizado". E14, que teve experiência em duas grandes empresas de auditoria, em uma delas como sócio, considera valer a pena trabalhar nestas organizações, não só em termos de crescimento profissional, mas também do ponto de vista financeiro.

"[...] não é todo mundo que vê a carreira de auditoria como uma oportunidade de aprendizado" (E6). Diante dessa afirmação de E6 é possível reforçar a percepção de que uma carreira organizacional em uma grande empresa, como as Big Four, para alguns, denota uma estratégia de autodesenvolvimento e compromisso consigo mesmo, muito característico de uma trajetória de carreira proteana. Por mais que se note uma escolha de carreira tradicional, os relatos podem suscitar a ação do indivíduo em sua trajetória: mesmo pertencente a um quadro fixo de progressão, as necessidades individuais são conhecidas e o desenho do percurso vai se estabelecendo de forma a alinhar-se com elas. Ou seja, o dinamismo de uma carreira organizacional em uma Big Four mostra uma inter-relação entre o que se considera tradicional e proteano no âmbito das carreiras.

A explicação dos motivos pelos quais a remuneração inicial nas Big Four é considerada muito baixa pela maioria dos entrevistados pode ser identificada no relato da terceira entrevistada:

Nesse quesito questão salarial versus investimento em treinamento é diferente das outras empresas. É diferente porque nos primeiros anos tu tá te formando ainda, e a Big, a empresa então investe muito mais e em contrapartida não, não investe tanto no teu salário inicial. E aí pra tentar ir equilibrando isso que acontecem essas questões das promoções anuais com $15,20,25 \%$ de aumento todo ano, pra tentar equilibrar, pra que tu chegue lá em gerente tu, tu esteja bem formado, em termos de conhecimento, de preparação, pra que, e que o teu salário valha a pena (E3).

O entrevistado 4 menciona que, para esse julgamento salarial, é importante considerar o momento de carreira em que se vive na Big Four: "a remuneração, pro trainee, eu acho adequada. Mas a partir do momento em que vai se desenvolvendo a carreira, eu acho que ela fica bem defasada em relação ao mercado".

O momento de carreira mencionado por E4 pode ter associação ao estágio de vida do indivíduo, que o aproxima da ideia de carreira sustentável (DE VOS; HEIJEN, 2015; MÜLLER; SCHEFFER; CLOSS, 2020). Os níveis de progressão na carreira de auditor de uma organização desse porte e perfil sustentam um conjunto de aspectos que transcendem a remuneração, tais como decisões pela continuidade e o contexto de vida. O momento de carreira vai além do organizacional, passando a transitar com maior frequência pelos espaços de lazer e família. Portanto, cabe refletir se a natureza do trabalho como auditor de uma Big Four, de certa forma, corrobora para a delimitação de um perfil profissional.

Observando os entrevistados, tem-se que sua grande maioria é composta por jovens de até 35 anos e, em grande parte, com formação acadêmica em pós-graduação. Assim, pelas idades de ingresso (maioria até 25 anos) é pertinente inferir que se trata de profissionais para os quais o trabalho foi ou é prioridade, porém que em contrapartida apresentam uma redução nas responsabilidades com família. É interessante pensar ainda que o trabalho de auditor numa Big Four é oportuno para determinados grupos sociais, numa visão de classe social.

Nesse sentido, percebe-se que o momento de carreira, as perspectivas profissionais e os investimentos em formação se relacionam à percepção de justiça e compensação em relação à remuneração.

\subsection{Progressão na carreira e crescimento dentro da Big Four}

Permanecer, e construir uma carreira em alguma das Big Four, não são tarefas fáceis, de acordo com a maioria dos entrevistados. Em relação às pessoas que permanecem nas Big Four, dois entrevistados trouxeram suas 
experiências em relação às pessoas que investem em sua carreira em uma Big Four: "na minha turma entraram 12 e a gente tem 2 lá ainda", disse a entrevistada 4, que trabalhou na Big de 2006 a 2008. Já o entrevistado 14, que ingressou na Big no final da década de 80, relembra: "nós éramos 17 profissionais, foi uma turma grande pra 88 . Nós éramos 17 profissionais na área tributária e, somando auditoria com tributária, nós éramos 43 . Desses 43,3 chegamos a sócios, 2 na auditoria na Big 1 e eu na área tributária na Big 2. Assim, menos de 10\%. De 43 profissionais, 3 ficaram".

Segundo o entrevistado 9, que ingressou na Big como trainee em 2004, aos 21 anos, enquanto ainda era estudante universitário, e hoje é diretor:

A minha carreira foi acelerada, mais acelerada que o normal. O pessoal leva pelo menos uns 15 anos ou mais pra chegar nesse cargo. Então eu acho que essa forma foi a expectativa. 0 que recebi de retorno foi melhor do que eu esperava. Mas normalmente quem fica numa firma de auditoria por mais tempo espera crescer (E9).

Para investir na sua carreira dentro de uma Big, permanecendo lá desde 2004, o entrevistado 10 revela a necessidade de um perfil workaholic': "Foram 3 anos seguidos e a promoção foi diferenciada por conta desse meu excesso de trabalho e da experiência que eu obtive"

A necessidade de um "perfil workaholic" e as desistências de muitos, leva-se a pensar que a ideia de autogestão de carreiro presente, seja na carreira proteana, sem fronteiras, seja caleidoscópica, vem, em contextos como o analisado, trazendo consigo uma exigência de disponibilização constante do sujeito, de dedicação para um trabalho que lhe demanda tempo e aperfeiçoamento constante.

Nesse tipo de trabalho nota-se a exigência de uma indissociação entre a vida pessoal e a vida profissional do funcionário, onde a vida profissional toma uma proporção significativa. Entretanto, a busca pelo equilíbrio entre vida profissional e pessoal tem sido trazida nas teorias contemporâneas de carreira como algo marcante. Desse modo, reforçase a percepção de que a trajetória de carreira numa Big Four exige um profissional com características pré-definidas e em conformidade com um estilo de carreira tradicional, pelo menos em um estágio de vida desses profissionais.

Nas reflexões sobre a sua carreira e o seu trabalho na Big, o entrevistado 13 trouxe, de uma forma bem sucinta, tudo o que foi dito pelos entrevistados: "o amadurecimento profissional é mais rápido em uma Big por viver, diariamente, diferentes situações em diferentes empresas, de diferentes setores. Além disso, a meu ver, o reconhecimento profissional chega mais cedo quando se trabalha em uma Big". Apesar desse reconhecimento, o E10 reflete sobre possibilidades que poderiam ter sido alcançadas:

Por ter esse perfil workaholic eu acho que eu errei na minha carreira no sentido de focar no trabalho, me colocar sempre à disposição e eu poderia ter aproveitado, ao longo da carreira, possibilidades de, é uma possibilidade que as Big Four dão né, de trancar a carreira, ir pra fora, estudar, enfim, depois voltar e seguir trabalhando. Enquanto eu era sênior eu poderia ter feito isso e não fiz porque como eu carregava o piano, digamos assim. Acabava que eles, eu pedia pra fazer isso, eles ficavam postergando, "vai depois, vai depois, vai depois", e o depois nunca chegava. Então um plano de carreira que eu tenho ainda é fazer isso, mesmo que seja forçadamente, mesmo no nível de carreira que eu tô hoje, o que é mais difícil né, que daí eu sou a fonte de receita e essa fonte de receita ia ficar 6 meses fora do Brasil. Então isso é algo que eu tenho vontade de fazer e que talvez seja uma briga aí pra que eu consiga fazer. E pode implicar talvez na minha saída da, da Big né (E10).

Ao falarmos aqui de carreira, especificamente a carreira nas Big Four, ela pode ser classificada, na literatura acadêmica, como carreira tradicional de progressões sucessivas. E2 destaca as possibilidades de crescimento, pelo esforço próprio: "Então isso é o que me motivava e continua me motivando até hoje né, depende simplesmente do esforço de cada um (E2)".

Ainda em relação à progressão de carreira na Big, os entrevistados 11, 10 e 5, e também a entrevistada 4, trouxeram um jargão que faz parte do cotidiano desse tipo de empresa: "congelar", que significa não promover naquele ano. "Todo ano tu é promovido ou tu é demitido né. Aí é difícil congelar, mas há alguns que acabam congelando os profissionais e aí grande parte acaba saindo né". Em outra contribuição importante, E3 compara as possibilidades de ascensão de carreira na Big com outros tipos de empresas para a profissão do contador:

Se eu entrasse em qualquer outra empresa, tipo, tem um contador por empresa, tu serias o analista contábil e só vai virar o contador, ou coisa, se o cara se aposentar, morrer, sair, sei lá. Então as tuas chances são muito restritas. E na Big Four tu, tu tá nadando numa raia que é só tua. Tu não precisa que ninguém saia, se dê mal, não tem aquela coisa de eu querer puxar o

$4 \quad$ Viciado em trabalho. 
tapete do outro, não. É tu fazer o teu trabalho bem feito e tu vai crescer, e tu vai ser reconhecido, e tu vai ter o teu sucesso (E3).

\subsection{Trajetórias de carreira}

O início da carreira nas Big Four se dá, normalmente, ingressando no cargo de trainee, salvo quando a contratação é por indicação, como foi comprovado com o relato de alguns entrevistados que tiveram esta experiência de ser indicado. Os entrevistados referem-se à necessidade de tempo disponível para viagens e dedicação à empresa, como aponta o entrevistado 14, com 27 anos de experiência em Big Four:

A única coisa que eu não gostava no começo, e aí eu acho que você tem que ter a questão de ter equilíbrio emocional né, pra, pra conviver bem com isso, é o fato de você não ser dono da tua vida né. Porque eu quando era assistente ou sênior, coisa assim, você nunca sabe onde você vai tá no dia seguinte né, você pode tá hoje, você pode tá trabalhando num escritório de Porto Alegre e amanhã você tá num cliente em Caxias, em Farroupilha, em qualquer outro lugar. Então assim, pra você programar a sua vida, às vezes, é um pouco complicado (E14).

E14 fala que a pessoa não é "dono da sua vida", como apontado por Meneses (2008), que refere que o auditor ou consultor perde o poder de decisão sobre o seu tempo, sobre sua rotina e até sobre a sua liberdade de ir e vir. Enfatiza que algum sócio, diretor ou gerente da Big será sempre responsável pelo o que o auditor fará no dia seguinte e, até mesmo, sobre as conquistas destas pessoas, sobre o seu destino enquanto fizerem parte da equipe de auditoria.

Nesse contexto, E14 comenta sobre alguns fatos do cotidiano de trainee: "se você é trainee, se ninguém te der trabalho você não tem o que fazer. No outro dia te enchem de trabalho e você tem que trabalhar até 10 horas da noite porque tem que fazer aquilo pra atender o cliente".

De acordo com a maioria dos entrevistados, a partir do cargo de gerente a remuneração começa a ser atrativa, a pessoa tem mais autonomia e começa a ter um pouco mais de qualidade de vida, pois há uma maior flexibilidade no trabalho. "Então tu quer um dia pegar uma tarde de folga, tu não precisa dar grandes satisfações pra ninguém. Tu pode pegar e sair. Então assim, questão de horário, fica mais, muitíssimo mais flexível" (E11).

O entrevistado 14, que passou por todos os cargos na antiga Big Five, e depois foi sócio por 15 anos em uma Big Four, faz sua análise sobre se as pessoas decidem ou não permanecer na Big Four e tornarem-se sócias:

Você paga um preço caro pra investir na tua carreira. E nem todos ficam por diversos fatores né. Pode ser questões pessoais que não tem condições de ir pra casa cedo, tem filhos, tem estrutura, uma necessidade financeira que, que não condiz com o que uma Big Four proporciona. (E14).

O relato do entrevistado 14 traz à discussão aspectos da trajetória de carreira que não são abordados nas falas dos entrevistados. O olhar externo de E14 à estrutura de uma Big Four mostra uma difícil realidade para a permanência numa organização desse tipo. Filhos, família, condições sociais e econômicas conflitam com o sonho de pertencer a uma Big Four. Assim, é oportuno relacionar aos modelos de carreira sustentável e caleidoscópico. Ponderar responsabilidades são características desses modelos. Eles trazem o trabalho emaranhado ao percurso de vida, portanto, abdicações ou escolhas convivem mutuamente com o momento de vida do profissional (consigo mesmo e com sua família). Desse jeito, interrupções podem ser comuns quando o trabalhador se encontra estabilizado em um posto de trabalho, fazendo com que ele parta em busca de outra oportunidade em que possa equilibrar o seu estágio de vida. Em relação à mulher, representada pela carreira caleidoscópica, é levado em consideração os diferentes papeis que exerce tanto profissional quanto pessoalmente. Por isso, três fatores são evidenciados nesse modelo de carreira: a) autenticidade (ser fiel a si mesma); b) equilíbrio (assertividade nas tomadas de decisão - sempre considerando o contexto pessoal e profissional) e c) desafio (ter autonomia para crescer e aprender, ter controle e capacidade de responsabilidade).

O entrevistado 11 refere que nessa busca é necessário haver uma revisão no objetivo de vida, no que se está em busca. "Se tu quiser virar sócio duma Big Four faz sentido tu continuar. Quando tu vira sócio não muda muito a tua atividade, muda salário, responsabilidade, mas tu continua vendendo projetos e sendo responsável técnico por projetos de consultoria" (E11).

Assim, é importante ressaltar ainda que, como demonstrado no Quadro 3, dos 14 entrevistados, 9 não permanecem atualmente nas Big Four. É possível perceber que destes 9 profissionais que não permaneceram na empresa, a maior parte já tinha alcançado os cargos de gerente ou sênior, o que contradiz o depoimento dos entrevistados, os quais afirmam que a partir do cargo de gerente a remuneração, a autonomia e a flexibilidade nestas empresas começam a ser mais atrativas, permitindo que o profissional tenha mais autonomia e mais qualidade de vida. Neste ponto as âncoras de carreira passam a ser questionadas ou alteradas, pois aqueles valores desejados, quando alcançados, deixam de ser os fatores que fazem com que os profissionais sigam trabalhando na mesma empresa. 


\section{CONSIDERAÇÕES FINAIS}

Retomando o objetivo deste estudo, que foi entender como auditores externos de Big Four percebem a sua carreira e qual a relação com a gestão de pessoas nessas organizações, no decorrer das análises ficou evidente que o trabalho nesse contexto exige um conjunto de competências, principalmente técnicas e conceituais, mas também ligadas à atitude, não só para a formação da trajetória de carreira, como também para a automanutenção do trabalhador nesse ambiente profissional. Gerir a si mesmo - administrando tempo e desafios -, ter disposição para abdicar de lazer e família, além de busca constante por desenvolvimento, foram os aspectos citados. Além disso, fazer carreira em uma Big Four supõe conviver dia a dia com metas e desafios. Isso se apresenta nos relatos dos entrevistados, que denunciam a "fria" atmosfera de produtividade.

Os relatos dos entrevistados se apresentam carregados de expectativas, tanto com o trabalho quanto com as políticas de gestão de pessoas agregadas pela organização. As falas destacam as políticas de treinamento e desenvolvimento, em primeiro plano, e a remuneração como aquelas que mais incentivam a permanência nesse ambiente de trabalho. Quanto à primeira, os investimentos em cursos de idioma, pós-graduações e outros cursos de capacitação, em conjunto com as possibilidades de experiências no exterior, se mostram atrativos e são atravessados pelas demandas individuais de desenvolvimento constante dos auditores. A remuneração, apontada algumas vezes como defasada a partir de um determinado estágio de carreira, acaba aparecendo em segundo plano na ordem de importância.

Quanto à carreira, ela se apresenta de forma tradicional, com etapas definidas e imaleáveis. Entretanto, ao indivíduo cabe saber se desenvolver em cada etapa da carreira, bem como saber adaptar-se. A ele estão incumbidos os desafios do cotidiano, viagens, etc., pois tem o conhecimento da trajetória a ser cursada. Logo, quando contrastada com os demais modelos de carreira (proteano, sem fronteiras, caleidoscópico, sustentável), nota-se uma carreira tradicional em um cenário histórico de transformações no mercado de trabalho (novos contratos de trabalho, novas formas e concepções de carreira e profissão etc.), sendo interseccionada pela demanda de autogestão, autodesempenho e autodesenvolvimento, traços destacados nas formas de carreira contemporâneas. A carreira organizacional (tradicional) mostra-se ainda atrativa, ainda mais em empresas com amplas políticas de gestão de pessoas, sendo uma via de acesso a um perfil característico de jovens em início de curso. Aos que lá permanecem, destaca-se a necessidade de manter dedicação e envolvimento intenso, que se aproxima de um perfil de "workaholic", tal como mencionado.

O olhar para si, para o seu crescimento e desenvolvimento; e a busca por experiências internacionais; são marcadores das outras formas de carreira objetivados na condução de uma carreira organizacional - algo que vem se delineando desde a década de 1980/90 com a quebra do paradigma da carreira agenciada exclusivamente pelas organizações até a década de 1970. Hoje, por mais que se disponha a trilhar carreira em uma organização, as aspirações individuais são salientes e, muitas vezes, com olhares voltados para o futuro. A vinculação à uma empresa pode estar associada a um plano de desenvolvimento individual, através da aquisição de experiências e competências as quais, talvez, não pudessem ser obtidas pela via individual do trabalhador. E é nesse sentido que os recentes modelos de carreira estão imbricados na carreira tradicional, entrelaçados nas expectativas individuais, nas tomadas de decisão, em suas necessidades profissionais e pessoais, nos contextos de vida.

Por vezes, as trajetórias em uma organização como as Big Four, diante das falas dos entrevistados, se confundem com uma estrutura determinante e seletiva de carreira. Essa afirmação busca denunciar "o que não é dito", mas é subjetivado no dia a dia do trabalho. Como exemplos, falamos de uma política de carreira que define e direciona unilateralmente o trabalhador na progressão da carreira; em detrimento ao relacional do trabalhador enquanto sujeito de responsabilidades múltiplas; uma neutralidade às diferentes realidades socioeconômicas dos funcionários - algumas vezes impeditiva da continuidade da trajetória de carreira; entre outras. Assim fazendo, querse lançar luz para a gestão sobre aspectos que são menos visíveis ou não reflexivos, sinalizando para um cenário contemporâneo de constantes transformações, o que inclui pensar as carreiras tradicionais e como se configuram, pois se entende como algo de importante contribuição para esse estudo.

Em relação às políticas de gestão de pessoas, seus investimentos não se tratam de um caso particular das Big Four para atração, retenção, manutenção das pessoas e para a garantia de sua competitividade. Em um ambiente competitivo, a presença de sólidas políticas e práticas de gestão de pessoas tem expressividade, além de se consolidar como fator potencial para a estratégia organizacional ao se encarregar do delineamento de um ambiente profissional qualificado, competitivo e diferenciado. Conforme demonstrado no depoimento de alguns entrevistados, a partir dessas políticas e práticas, é possível notar que as Big Four possuem uma forte cultura empresarial, capaz de ser refletida até mesmo na conduta de profissionais de diferentes países, com diferentes características e formações, como foi relatado por aqueles que tiveram a experiência de realizar intercâmbio para outras sedes das empresas pesquisadas.

Como sugestão de estudos futuros, propõe-se acompanhar a trajetória dos que saíram dessas empresas. O que foram buscar? Como veem suas carreiras após essa experiência? Tais questões apresentam, portanto, um campo de estudo ainda oportuno de se aprofundar. 


\section{REFERÊNCIAS}

ALBUQUERQUE, Lindolfo Galvão de. Estratégias de recursos humanos e competitividade. Administração contemporânea: perspectivas e estratégias. São Paulo: Atlas, p. 215-238, 1999.

ALMEIDA, Martinho Isnard Ribeiro de; TEIXEIRA, Maria Luiza Mendes; MARTINELLI, Dante Pinheiro. Por que administrar estrategicamente recursos humanos?.Revista de Administração de Empresas, [S. I.] v. 33, n. 2, p. 12-24, 1993.

ARTHUR, Michael. B. The boundaryless career: a new perspective for organizational inquiry. Journal of Organizational Behavior, [S. I.], v. 15, n. 4, 1994. Special issue.

ASHTON, Chris; HAFFENDEN, Mike; LAMBERT, Andrew. The "fit for purpose" HR function. Strategic HR Review, [S. I.], v. 4, n. 1, p. 32-35, 2004.

BARDIN, Laurence. Análise de conteúdo.Lisboa: Ed. 70, 1991.

BARUCH, Y.; REIS, C. How global are boundaryless careers and how boundaryless are global careers? Challenges and a theoretical perspective. Thunderbird International Business Review, [S. I.], v. 58, n. 1, p. 13-27, 2016.

BENDASSOLLI, Pedro Fernando. Psicologia e trabalho. Apropriações e significados. São Paulo: Cengage Learning, 2009.

BOXALL, Peter; PURCELL, John. Strategy and human resource management. [S. I.]: Palgrave, 2011.

CANÇADO, Vera. L. et al. Revisitando as quatro faces da gestão de recursos humanos. In:ENCONTRO DAANPAD, 41., 2017, São Paulo. Anais [...]. São Paulo: ANPAD, 2017p. 1-17.

CÉSAR, Ana Maria RouxValentini Coelho; CODA, Roberto; GARCIA, Mauro Neves. Um novo RH?-avaliando a atuação e o papel da área de RH em organizações brasileiras. FACEF Pesquisa-Desenvolvimento e Gestão,[S. I.], v. 9, n. 2, 2010.

CHANLAT, Jean-François. Quais carreiras e para qual sociedade.RAE Revista de Administração de Empresas. São Paulo. v. 35, n. 6, p. 67-75, nov./dez. 1995.

DE VOS, Ans; HEIJEN, Beatrice. Sustainable careers: introductory chapter. In: De Vos, An; HEIJDEN, Van der (ed.). Handbook of research on sustainable careers. Cheltenham: Edward Elgar, p. 1-19. 2015.

DELHVI, S. S.; SÜß, S. Careers and career research in Germany: a literature review. Management Review Quarterly, [S. I.], v. 66, n. 1, p. 1-31, 2016.

DEMO, Gisela et al. Políticas de gestão de pessoas no novo milênio: cenário dos estudos publicados nos periódicos da área de administração entre 2000 e 2010. Revista de Administração Mackenzie, [S. I.],v. 12, n. 5, 2011.

FISCHER, André Luiz. Um resgate conceitual e histórico dos modelos de gestão de pessoas. In: FISCHER, André Luiz. As pessoas na organização. São Paulo: Gente, 2002. v. 1, p. 11-34.

FRAGA, Aline Mendonça; ROCHA-DE-OLIVEIRA, Sidinei. Mobilidades no labirinto: tensionando as fronteiras nas carreiras de mulheres. Cadernos EBAPE. BR, [S. I.] v. 18, n. spe, p. 757-769, 2020.

GALLON, Shalimar; SCHEFFER, Angela Beatriz Busato. Expatriação: uma oportunidade de repensar a carreira. Revista Alcance.[S. I.], v. 22, n. 2. p. 298-315, abr./jun. 2015.

GIL, Ana. Conciliação entre vida profissional e vida familiar: o caso da dependência. Lisboa: Instituto da Segurança Social, 2009.

GODOY, Arlida Schmidt. Introdução à pesquisa qualitativa e suas possibilidades. Revista de administração de empresas, [S. I.], v. 35, n. 2, p. 57-63, 1995. 
GRANGEIRO, Rebeca da Rocha; NADAE, Jeniffer de; BARRETO, Augusto Tavares Paes. Produção científica sobre carreira em periódicos de administração: uma análise bibliométrica. Caderno Profissional de Administração da UNIMEP, [S. I.], v. 9, n. 1, p. 18-47, 2020.

GUBLER, M.; BIEMANN, T.; TSCHOPP, C.; GROTE, G. How career anchors differentiate managerial career trajectories. Journal of Career Development, [S. I.], v. 42. n.5, p. 412-430, 2015.

HALL, Douglas T. Careers in Organization. Pacific Paradise: Goodyer Company, 1976.

HALL, Douglas T.; MIRVIS, Philip H. Psychological success and the boundaryless career. Journal of Organizational Behavior, [S. I.] v. 15, p. 365-380, 1994.

HALL, Douglas T. Protean careers of the 21st century. Academy of Management Executive, [S. I.], v.10, n.4, p.816, Nov. 1996.

INKSON, Kerr. Images of career: nine key metaphors. Journal of Vocational Behavior, [S. I.], v. 65, n. 1, p. 96-111, 2004.

LACOMBE, Beatriz Maria Braga; BENDASSOLLI, Pedro F. Cinco décadas de RH. GV-executivo, [S. I.], v. 3, n. 3, p. 65-69, 2004.

LENGNICK-HALL, Mark L. et al. Strategic human resource management: the evolution of the field. Human resource management review, [S. I.], v. 19, n. 2, p. 64-85, 2009.

MAINIERO, Lisa A.; SULLIVAN, Sherry E. Kaleidoscope careers: an alternate explanation for the "opt-out "revolution. Academyof Management Perspectives, [S. I.], v. 19, n. 1, p. 106-123, 2005.

MAINIERO, L. A.; GIBSON, D. E. The kaleidoscope career model revisited: how midcareer men and women diverge on authenticity, balance, and challenge. Journal of Career Development, v. 45, n. 4, p. 361-377, 2018.

MENESES, Ana Beatriz FernandesBezerra de. Trabalho imaterial e subjetividade em atividades de auditoria e consultoria. 2008. 123 f. Dissertação (Mestrado em Administração) - Escola de Administração, Universidade Federal do Rio Grande do Sul, Porto Alegre, 2008.

MÜLLER, Camila Vieira; SCHEFFER, Angela Beatriz Busato; CLOSS, Lisiane Quadrado. Uma viagem pode transformar a sua vida: experiências de vida e carreira na contemporaneidade. Administração: Ensino e Pesquisa, [S. I.], v. 21, n. 3, p. 425-453, 2020.

O'NEILL, M. S.; JEPSEN, D. Women's desire for the kaleidoscope of authenticity, balance and challenge: a multimethod study of female health workers' careers. Gender, Work \& Organization, [S. I], v. 26, n. 7, p. 962-982, 2019.

PAROLIN, Sonia Regina Hierro; ALBUQUERQUE, Lindolfo Galvão de. Gestão estratégica de pessoas para a inovação: o caso da Frimesa Cooperativa Central. Revista de Administração da UFSM, [S. I.], v. 4, n. 1, p. 105-124, 2011.

PURCELL, John. Understanding the people and performance link: unlocking the black box. London: CIPD Publishing, 2003.

SCHEIN, Edgar H. Career anchors revisited: implications for career development in the 21st Century. The Academy of Management Executive, [S. I.], v. 10, n. 4, p. 80-88, 1996. Link

SCHEIN, E. H.; VAN MAANEN, J. Career anchors and job/role planning. Organizational Dynamics, [S, I,], v. 45, n. 3, p. 165-173, 2016.

SULLIVAN, Sherry. E., MANIERO, Lisa. Using the kaleidoscope career model to understand the changing patterns of women's careers: designing HRD programs that attract and retain women. Advances in Developing Human Resources, [S. I.], v. 10, n. 1, p. 32-49, 2008.

TANURE, Betania; EVANS, Paul; CANÇADO, Vera L. As quatro faces de RH: analisando a performance da gestão de recursos humanos em empresas no Brasil. Revista de Administração Contemporânea, [S. I.], v. 14, n. 4, p. 594-614, 2010. 
THIRY-CHERQUES, Hermano Roberto. Individualismo e Carreira: o duplo constrangimento. In: BALASSIANO, Moisés; COSTA, Isabel de Sá Affonso da. Gestão de Carreiras: dilemas e perspectivas. São Paulo: Atlas, 2006. cap. 2, p. 21-48.

ULRICH, David. Os campeões de recursos humanos: inovando para obter os melhores resultados. Birigui: Futura, 1998.

VELOSO, Elza Fátima Rosa; DUTRA, Joel Souza. Processo de transição de carreira. In: DUTRA, Joel Souza. (org.) Gestão de carreiras na empresa contemporânea. São Paulo. Atlas, 2010.

VIEIRA, Adriane et al. Um estudo das relações entre gênero e âncoras de carreira. Cad. EBAPE.BR, Rio de Janeiro, v. 17, n. 3, p. 577-589, Sept. 2019.

\section{Contato:}

Carla dos Santos Feijó

E-mail: carla.feijo@badesul.com.br

Angela Beatriz Busato Scheffer

E-mail: angela.scheffer@ufrgs.br

Jhony Pereira Moraes

E-mail: jhonymoraes@hotmail.com.br

Arthur Gehrke Martins Andrade

E-mail: arthur_gma@hotmail.com 